\title{
Synergistic inhibition of SCR1- and ERBB2-driven brain metastatic breast cancer cells
}

\author{
Shahnaz R. Ansari', Zain Jandial'1, Xiwei Wu², Xueli Liư3, Mike Y. Chen'1, Khairul I. Ansari' \\ 'Division of Neurosurgery, Beckman Research Institute, City of Hope, Duarte, CA 91010, USA. \\ 2Department of Molecular and Cellular Biology, Beckman Research Institute, City of Hope, Duarte, CA 91010, USA \\ ${ }^{3}$ Division of Biostatistics, Beckman Research Institute, City of Hope, Duarte, CA 91010, USA.
}

Correspondence to: Dr. Khairul I. Ansari, Division of Neurosurgery, Beckman Research Institute, City of Hope, Duarte, CA 91010, USA.E-mail: kansari@coh.org

How to cite this article: Ansari SR, Jandial Z, Wu X, Liu X, Chen MY, Ansari KI. Synergistic inhibition of SCR1- and ERBB2-driven brain metastatic breast cancer cells. J Cancer Metastasis Treat 2019;5:20. http://dx.doi.org/10.20517/2394-4722.2018.68

Received: 24 Oct 2018 First Decision: 14 Jan 2019 Revised: 18 Jan 2019 Accepted: 6 Feb 2019 Published: 22 Mar 2019

Science Editor: William P. Schiemann Copy Editor: Cai-Hong Wang Production Editor: Huan-Liang Wu

\begin{abstract}
Aim: Metastasis to the brain has become a major limitation to the life expectancy and quality of life for many patients with breast cancer. Unfortunately, other than radiation and palliative treatments with trastuzumab, and pertuzumab, no effective therapy for brain metastases is currently available. This study seeks to identify novel gene targets and pharmaceutical Intervention against breast cancer brain metastasis.
\end{abstract}

Methods: The detailed methods applied to this study, including comparative RNA sequencing and bioinformatics analysis of sequence data, ingenuity pathway analysis, protein-protein interaction analysis, high throughput screening of clinical and pre-clinical drugs, cell viability and proliferation assay, toxicity and apoptosis assay using fluorescenceactivated cell sorting, real-time PCR, western blotting, statistical analysis of data.

Results: The study reveals critical roles for SRC, ERBB2, PIK3CA, and GABA in the proliferation and survival of breast cancer brain metastatic (BBM) cells and showed that SRC- and ERBB2-mediated activation of PIK3-AKT/mTOR signaling regulates BBM cell survival. Selective inhibition of these candidate genes alone or in combination induces robust apoptosis in BBM cells

Conclusion: The findings of this study provide a rationale for further preclinical evaluation of SRC-targeting regimens in combination with ERBB2 inhibitors and/or GABA agonists to target breast cancer brain metastasis.

Keywords: Breast cancer, brain metastasis, human epidermal growth factor receptor 2, ERBB2, SRC, astrocytes, PI3KCA

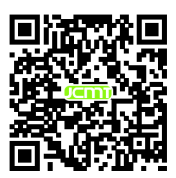




\section{INTRODUCTION}

Brain metastases represent a significant clinical challenge for the treatment of patients with human epidermal growth factor receptor 2 (HER2)-positive breast cancer. Although modern multimodality therapies have improved the survival of patients with primary breast cancer and systemic metastases, the overall median survival of patients with brain metastases is dismally less than one year ${ }^{[1,2]}$. Furthermore, as the brain represents a "sanctuary site" for HER2+ metastases, and has comprised a larger proportion of relapse sites over time ${ }^{[3,4]}$. Despite this increasing incidence, there is no current consensus on therapy for those with intracranial progression ${ }^{[5,6]}$. Current clinical options for HER2+ brain metastases patients are limited to trastuzumab (anti-HER2 monoclonal antibody) treatment in conjunction with whole-brain radiotherapy or stereotactic radiosurgery ${ }^{[7]}$, neither of which clinically effective in treating life-threatening brain metastases that often lead to severe cognitive complications.

The poor prognosis of breast cancer brain metastatic (BBM) patients with local therapies underscores the need for better systemic treatments. Over the last few years, preclinical and clinical progress in the treatment of BBM has led to novel hypotheses for improving therapeutic outcome. The limited efficacy of trastuzumab against $\mathrm{BM}$ is often attributed to an inadequate penetration through the $\mathrm{BBB}^{[8]}$. Lapatinib, a small molecule kinase inhibitor of epidermal growth factor receptor (EGFR) and HER2, was evaluated in BCBM due to its ability to better penetrate the BBB than trastuzumab ${ }^{[9,10]}$. The success of lapatinib and capecitabine in preventing brain metastasis led to its inclusion in patients with established brain metastases. New generation ErbB family inhibitors neratinib and afatinib are more potent and specific than lapatinib, showed significant responses in limited cases of $\mathrm{BBM}^{[11]}$. The downstream HER2 signaling inhibitors including the PI $3 \mathrm{~K}$ inhibitor BKM120 and the mTOR inhibitor everolimus were evaluated to overcome de novo or acquired resistance to anti-HER2 therapy. Indeed, targeting the HER2 family member HER3, critical for HER2 downstream signaling, enhances the efficacy of HER2-targeted therapies in preclinical models of $\mathrm{BBM}^{[12,13]}$.

Recent clinical findings described the efficacy of antibody-based therapy in BBM. Upon treatment Bevacizumab and trastuzumab-DM1 adequately accumulate in brain metastatic lesions to exert positive effect $^{[14-17]}$. Antibody-chemotherapy conjugate such as ado-trastuzumab emtansine (T-DM1) was approved for the treatment of HER2-positive breast cancer due to its higher efficacy over lapatinib and capecitabine in patients with disease progression after trastuzumab ${ }^{[18]}$. As T-DM1 targets acquired or microenvironmentmediated activation of Her2 independent signaling pathways, this agent would be expected to be effective in such patients.

Using RNA sequencing (RNA-seq) analysis of primary HER2+ breast cancer and HER2+ breast to brain metastatic tumor resections, along with normal breast and normal brain tissues, we demonstrated that SRC- and ERBB2-mediated regulation of PI3K-AKT/mTOR signaling plays a critical role in BBM cell proliferation $^{[19]}$. Inhibition of SRC, ERBB2, and downstream kinases induced robust apoptotic cell death. In parallel experiments, we conducted a high throughput screening of 1650 clinical and preclinical drug candidates and found that activation of GABA signaling using a GABA agonist induces apoptosis in the breast to brain metastatic cells.

Interestingly, it has been shown that the SRC family of non-receptor tyrosine kinases is critical for both HER2+ and triple-negative breast cancer ${ }^{[20]}$. SRC activation maximizes the HER2: HER3 interaction and serves as a convergent point of multiple downstream signals, including the PI3K-AKT/mTOR pathway, thus regulating cell viability ${ }^{[20,21]}$. Similarly, activation of GABA signaling negatively regulates not only neural stem cells but also embryonic and cancer stem cells ${ }^{[22-24]}$. GABAergic breast to brain metastatic cells rely on GABA as an energy source, and activation of GABA signaling prevents cell proliferation directly or by blocking the supply of GABA to the invading cells. This collective evidence suggests that inhibiting HER2 and simultaneous targeting SRC and/or GABA is a promising strategy for the treatment of breast cancer brain metastasis. 


\section{METHODS}

\section{Patient consent and tissue processing}

De-identified archival and fresh tumor tissue samples were collected from consented patients undergoing resection of primary breast or breast to brain metastases, in accordance with a City of Hope Institutional Review Board (IRB)-approved protocol (\#05091).

\section{RNA isolation and sequencing}

The flash frozen patient tissue samples were subjected to total RNA preparation using an RNeasy Mini Kit (Qiagen), according to the manufacturer's instructions, eluted in $50 \mu \mathrm{L}$ of RNase/DNase-free water, and the initial concentration and purity assessed on a NanoDrop ND-1000 spectrophotometer (NanoDrop Technologies, Wilmington, DE). Prior to sequencing, RNA quality was assessed by microfluidic capillary electrophoresis using an Agilent 2100 Bioanalyzer and the RNA 6000 Nano Chip kit (Agilent Technologies, Santa Clara, CA). Sequencing libraries were prepared with the TruSeq RNA Sample Prep Kit V2 (Illumina, San Diego, CA), according to the manufacturer's protocol with minor modifications. Briefly, ribosomal RNA was removed from 500 ng of total RNA using a RiboZero kit (Illumina) and the resulting RNA was ethanol precipitated. Pellets were re-suspended in $17 \mu \mathrm{L}$ of Elute/Prime/Fragment Mix (Illumina) and first-strand cDNA synthesis performed using DNA polymerase I and RNase H. cDNA was end repaired, 3 ' end adenylated, and universal adapter ligated followed by 10 cycles of PCR using Illumina PCR Primer Cocktail and Phusion DNA polymerase (Illumina). Libraries were purified with Agencourt AMPure XP beads, validated with the Agilent 2100 Bioanalyzer, and quantified with Qubit (Life Technologies). Libraries were sequenced on an Illumina Hiseq 2500 with single-end 40-bp reads. Raw sequences were aligned to the human genome assembly (version 19, GRCh37.p13) using Tophat v2 and RefSeq gene expression levels were counted using HTseq-count. The genes expression counts were normalized using the trimmed mean of M-values method implemented in the Bioconductor package "edgeR." The differential expression analysis, clustering analysis, and pathway analysis were conducted using the DAVID online annotation tool and Ingenuity Pathway Analysis (IPA) to determine tissue-specific gene signatures and signaling pathways. The gene expression data of candidate genes was confirmed by real-time PCR.

\section{Breast cancer brain metastasis cell cultures}

HER2+ tumor samples were acquired from patients undergoing resection of the breast to brain metastases in accordance with a City of Hope IRB-approved protocol (IRB \#05091). A portion of each specimen was cultured in DMEM-F12 (Life Technologies) supplemented with 10\% fetal bovine serum, 1\% glutamax, and $1 \%$ antibiotic-antimycotic(Life Technologies) in collagen-coated T75 flasks (Life Technologies) to derive lowpassage primary cell lines COH-BBM1 (BBM1) and $\mathrm{COH}-\mathrm{BBM} 2(\mathrm{BBM} 2)$.

\section{High throughput screening of therapeutic candidates}

The Lopac 1280 compound library (Sigma), DiscoveryProbe Neuronal Signaling Library (ApexBio), and clinical drugs targeting primary breast cancer and CNS tumors (Cayman Chemical) were obtained commercially. All the compounds of the two libraries are in preclinical or clinical candidates. Over 50\% compounds of the library target neural disorders. The compounds were dissolved in DMSO at concentrations of $100 \mu \mathrm{mol} / \mathrm{L}$. For the initial screening, BBM1 cells were grown in 96-well plates (10000/well) and treated with the compounds at a final concentration of $1 \mu \mathrm{mol} / \mathrm{L}$ ( $n=3$ per treatment). Control cells were treated with DMSO only. The viability of the cells was measured at 48 and $72 \mathrm{~h}$ post-treatment by using a CellTiterGlo Luminescent Cell Viability Assay kit (Promega). The compounds that suppressed BBM1 cell viability by at least 70\% compared to the control were selected for secondary screening in both BBM1 and BBM2 cells lines. The compounds that showed consistent toxicity of both BBM1 and BBM2 cells over a period of 10 days were assessed for toxicity against BBM1 cells but not astrocytes.

To analyze cell type-specific toxicity, human astrocytes and BBM1 cells were grown overnight prior to treatment with $1 \mu \mathrm{mol} / \mathrm{L}$ of the active compounds $(n=6)$. Control cells were treated with DMSO only. The 
viability of the cells was measured at 48 and $72 \mathrm{~h}$ post-treatment using the CellTiter-Glo Luminescent Cell Viability Assay kit. Compounds that showed at least two-fold greater toxicity against BBM1 cells compared to astrocytes cells were further analyzed for their concentration-dependent effects on BBM1 cells. For concentration-dependent toxicity, cells were treated with $0,31.2,62.5,125,250,500,1000 \mathrm{nmol} / \mathrm{L}$ final concentration of the compounds $(n=8)$. The viability was measured at $72 \mathrm{~h}$ post-treatment. The data normalization compared to control and $\mathrm{IC}_{50}$ determination was done using GraphPad Prism 7.

\section{Real-time PCR and Western blot analysis}

Total RNA from astrocytes and BBM1 and BBM2 cells was extracted using Trizol (Invitrogen) and treated with RNase-free DNase (Qiagen), according to the manufacturer's instructions. To analyze gene expression, cDNA was synthesized using an iScript reverse transcription kit (Bio-Rad). Real-time PCR quantification was conducted using gene-specific primers and SYBR Select Master Mix (Applied Biosystems) using a CFX real-time PCR system (Applied Biosystems). Control PCR reactions were conducted using glyceraldehyde3-phosphate dehydrogenase (GAPDH) and/or actin-specific primers. PCR data was analyzed using the CFX manager (Bio-Rad).

For Western blot analysis, total cell lysates were prepared in protein lysis buffer $(50 \mathrm{mmol} / \mathrm{L}$ Tris- $\mathrm{HCl}, \mathrm{pH}$ 7.5; $100 \mathrm{mmol} / \mathrm{L} \mathrm{NaCl} ; 1 \%$ Triton X-100; $1 \mathrm{mmol} / \mathrm{L}$ EDTA; $1 \mathrm{mmol} / \mathrm{L}$ EGTA, $50 \mathrm{mmol} / \mathrm{L} \beta$-glycerophosphoran, $1 \mathrm{mmol} / \mathrm{L}$ dithiothreitol, $1 \mathrm{mmol} / \mathrm{L}$ phenylmethanesulfonyl fluoride; $2 \mathrm{mmol} / \mathrm{L}$ sodium orthovanadate, $10 \mu \mathrm{g} / \mathrm{mL}$ aprotinin; $10 \mu \mathrm{g} / \mathrm{mL}$ leupeptin; and $10 \mu \mathrm{g} / \mathrm{mL}$ pepstatin A) by incubating cells for $20 \mathrm{~min}$ at $4{ }^{\circ} \mathrm{C}$, followed by centrifugation $\left(15000 \times g, 15 \mathrm{~min}, 4^{\circ} \mathrm{C}\right)$. Protein extracts were analyzed by using antibodies specific to ERBB2; phosphorylated ERBB2 (pERBB2); Protein kinase B (AKT); phosphorylated AKT (pAKT) were obtained from Millipore; Phosphatidylinositol-4,5-Bisphosphate 3-Kinase Catalytic Subunit, Alpha (PIK3CA), phosphorylated PIK3CA (pPIK3CA); SRC Proto-Oncogene (SRC); phosphorylated SRC (pSRC); MYC Proto-Oncogene (MYC); Mammalian Target of Rapamycin (mTOR); phosphorylated mTOR (pmTOR); procaspase 3 and cleaved caspase 3 were obtained from Cell Signaling. Actin and $\alpha$-tubulin antibodies were also obtained from Cell Signaling.

\section{Apoptosis analysis}

Apoptosis induction in treated and control cells was measured using Annexin V-FITC staining followed by FACS analysis. In brief, cells were treated with the compounds 24 to $48 \mathrm{~h}$ prior to fixing in $4 \%$ PFA. Control cells were treated with vehicle alone. The cells were immunostained with Annexin V-FITC (Invitrogen) followed by PI (Life Technology) and analyzed using BD FACSAria Flow Cytometer (BD Biosciences). The experimental control cells were stained with IgG with or without PI.

\section{Statistical analysis}

Verification of RNA-seq data was done with real-time PCR in at least three biological replicates to confirm reproducibility and repeated at least twice. Results are expressed as the means \pm SEM. Unless otherwise stated, the two groups comparisons analyses were performed by using Mann-Whitney $U$ tests in GraphPad Prism $^{\bullet} 7.0$ (GraphPad Software Inc., La Jolla, CA, USA). $P<0.05$ was considered to be statistically significant.

\section{RESULTS}

\section{Breast cancer brain metastases display a unique brain-like transcription profile}

Primary HER2(ERBB2)+ breast cancer tissue (PT) and HER2+ breast to brain metastatic tissue (MT) collected from the consented patients, along with normal breast (nBreast) and normal brain (nBrain) tissues, were subjected to RNA-seq analysis. Hierarchical clustering of the normalized expression data of 20,257 transcripts revealed that, whereas PT shows transcriptome similarity with nBreast tissue, MT exhibits a brain-like transcription profile [Figure 1A and B]. IPA of the 367 MT-specific revealed ERBB2 signaling as a 
A
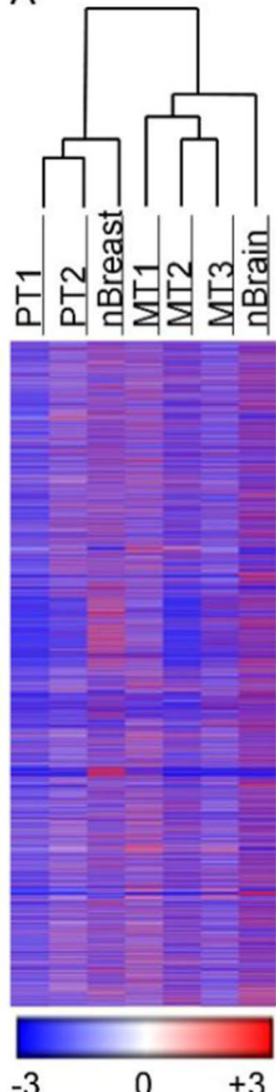

B

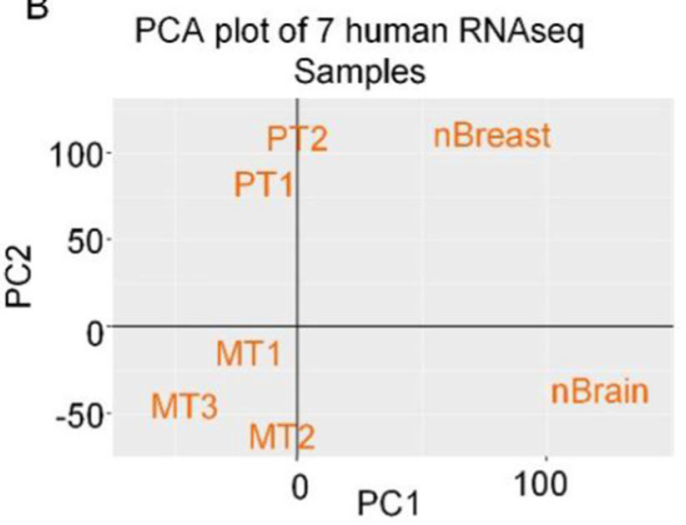

D

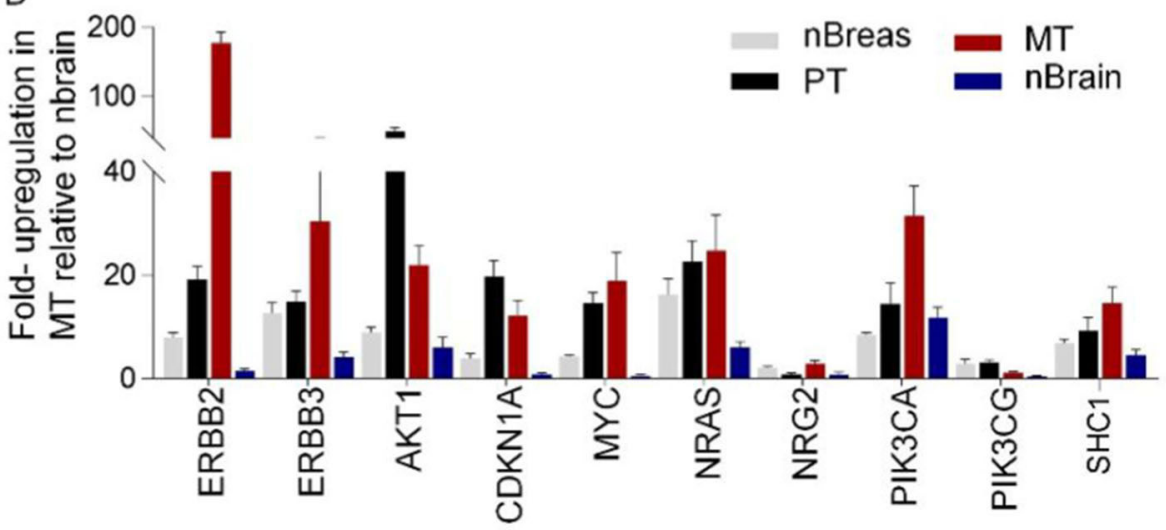

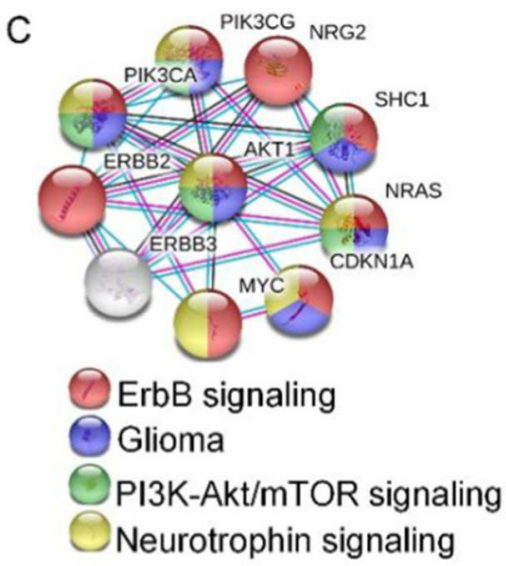

nBreas $\rightleftharpoons$ MT - $\mathrm{PT}$ nBrain

Figure 1. RNA-Seq analysis of two primary breast tumors (PT1-2), one normal breast tissue sample (nBreast), three breast to brain metastatic tumors (MT1-3), and one normal brain tissue sample (nBrain). A: Heatmap comparison of gene expression in each group, presented as log2-normalized fragments per kilobase of transcript per million mapped reads (FPKM). Colors indicate relatively low (blue) or high (red) gene expression; B: the principal component analysis (PCA) of $\log _{2}$-normalized FPKM values, showing similarities and differences between sample groups; C: protein-protein interactions of selected genes overexpressed in metastatic tissue (MT) samples compared to all other groups; D: real-time PCR quantification of genes overexpressed in different samples $(n=3, P<0.05)$. Error bars indicate SEM

major canonical pathway overexpressed in MT [Supplementary Figures 1 and 2]. Protein-protein interaction analysis of the MT-specific genes revealed $\mathrm{ERBB} 2 / \mathrm{PI} 3 \mathrm{~K} / \mathrm{AKT} / \mathrm{mTOR}$ as a potential major regulator of the breast to brain metastatic cell survival and proliferation [Figure 1C]. Similarly, KEGG pathway analysis projected ERBB2, PIK3-Akt/mTOR, and neurotrophin signaling as major pathways associated with MTspecific genes [Supplementary Figure 2].

Based on IPA, followed by protein-protein interaction and KEGG pathway analyses, we focused on a set of 10 genes that showed at least two-fold overexpression in MT tissue compared to all other groups and may be important for the proliferation of BBM cells.

To confirm the expression of these genes, we synthesized gene-specific primers and performed real-time PCR analysis of RNA extracted from MT (MT1-3), PT (PT1-2), and nBrain tissue [Figure 1D]. To further confirm the expression of these MT-specific genes, we cultured two BBM tissue-derived low-passage cell lines, BBM1 and BBM2, along with human reactive astrocytes. Both BBM cell lines showed distinct morphological differences compared to astrocytes [Figure 2A]. The real-time PCR analysis of extracted RNA showed significant $(P<0.05)$ upregulation of MT-specific genes, except for NRG2 and PIK3CG, in BBM cells compared to astrocytes [Figure $2 \mathrm{~B}]$. 
A

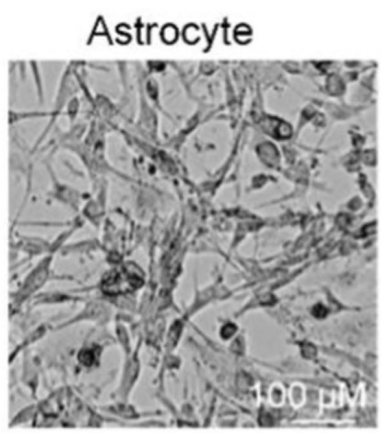

BBM1

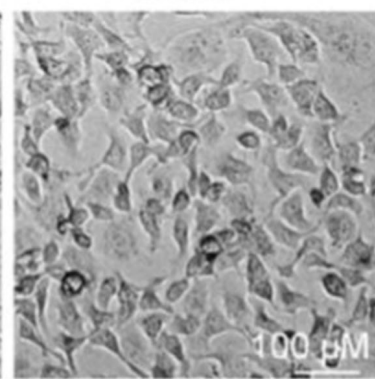

BBM2

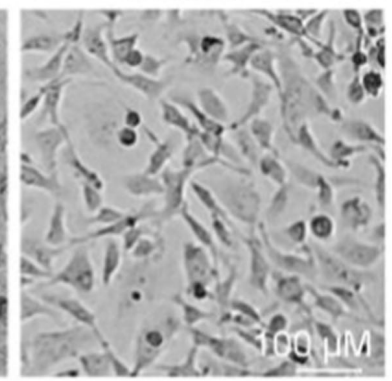

$\mathrm{B}$

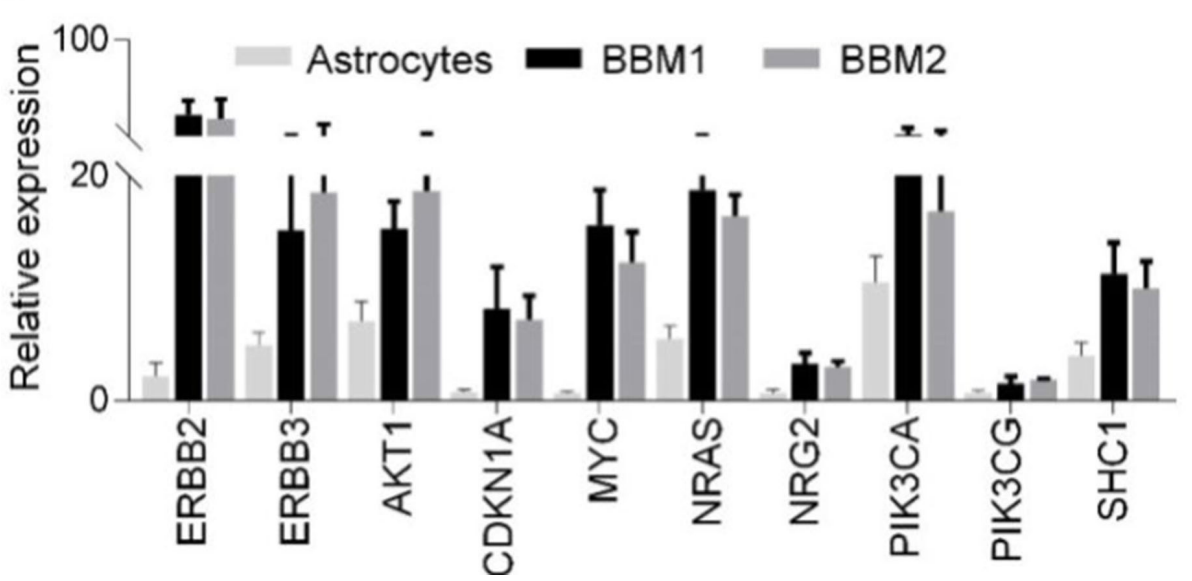

Figure 2. A: Bright field images of human Astrocytes and breast cancer brain metastasis 1 (BBM1) and 2 (BBM2) cells showing morphological differences between cell lines. Scale bars $=100 \mu \mathrm{mol} / \mathrm{L}$; B: real-time PCR analysis of genes enriched in Astrocytes and $\mathrm{BBM}(\mathrm{BBM} 1$ and BBM2) cells $(n=3, P<0.05)$. Error bars indicate SEM

\section{Disruption of ERBB2 and the PIK3/AKT/mTOR signaling pathway induces apoptosis in BBM cells}

Bioinformatics analysis of our sequence data, published data, and previous findings from our lab indicate MT-specific ERBB2-mediated activation of the PI3K-AKT/mTOR pathway [Figure 3A]. We found expression of ERBB2, PIK3CA, and MYC was 20, 8 and 4 fold, higher in HER2+ MT tissue compared to PT, indicating the potential function of the neural microenvironment in substantially increasing their expression. To confirm the function of ERBB2 on PI3K-AKT/mTOR signaling, we treated BBM1 cells with $50 \mathrm{nmol} / \mathrm{L}$ of the ERBB2 inhibitor Lapatinib or the PIK3CA inhibitor Idelalisib for $48 \mathrm{~h}$. Western blot analysis of total protein extracts showed that Lapatinib and Idelalisib inhibited phosphorylation of ERRB2, PIK3CA, AKT, and mTOR [Figure 3B]. To confirm the effects of the inhibitors on cell viability, BBM1 cells were treated with various concentrations $(0,31.2,62.5,125,250,500,1000 \mathrm{nmol} / \mathrm{L})$ of Lapatinib and Idelalisib, as well as inhibitors of AKT (AZD5363) and mTOR phosphorylation (Rapamycin). Our analysis showed that treatment with each of the inhibitors suppressed cell viability [Figure 3C]. Lapatinib induced the highest inhibition of $\mathrm{BBM} 1$ cell proliferation with an $\mathrm{IC}_{50}$ value of $25.1 \mathrm{nmol} / \mathrm{L}$ at $72 \mathrm{~h}$ post-treatment.

\section{Drug screen indicates that SRC, ERBB2, and GABA signaling pathways play critical roles in BBM1 cell proliferation}

To identify novel clinical or preclinical drug candidates to target breast cancer brain metastasis, we performed a high throughput screening of 1,650 compounds. Preliminary screening was done by treating BBM1 cells with $1 \mu \mathrm{mol} / \mathrm{L}$ of each compound for $72 \mathrm{~h}$. We identified 105 compounds that showed robust toxicity (at least 70\% inhibition) against BBM1 cells [Figure 4A].

In a secondary screening, we analyzed the consistency and stability of the compounds against two HER2+ $\mathrm{BBM}$ cell lines (BBM1 and BBM2). Cells were treated with $50 \mathrm{nmol} / \mathrm{L}$ of each compound and analyzed over 

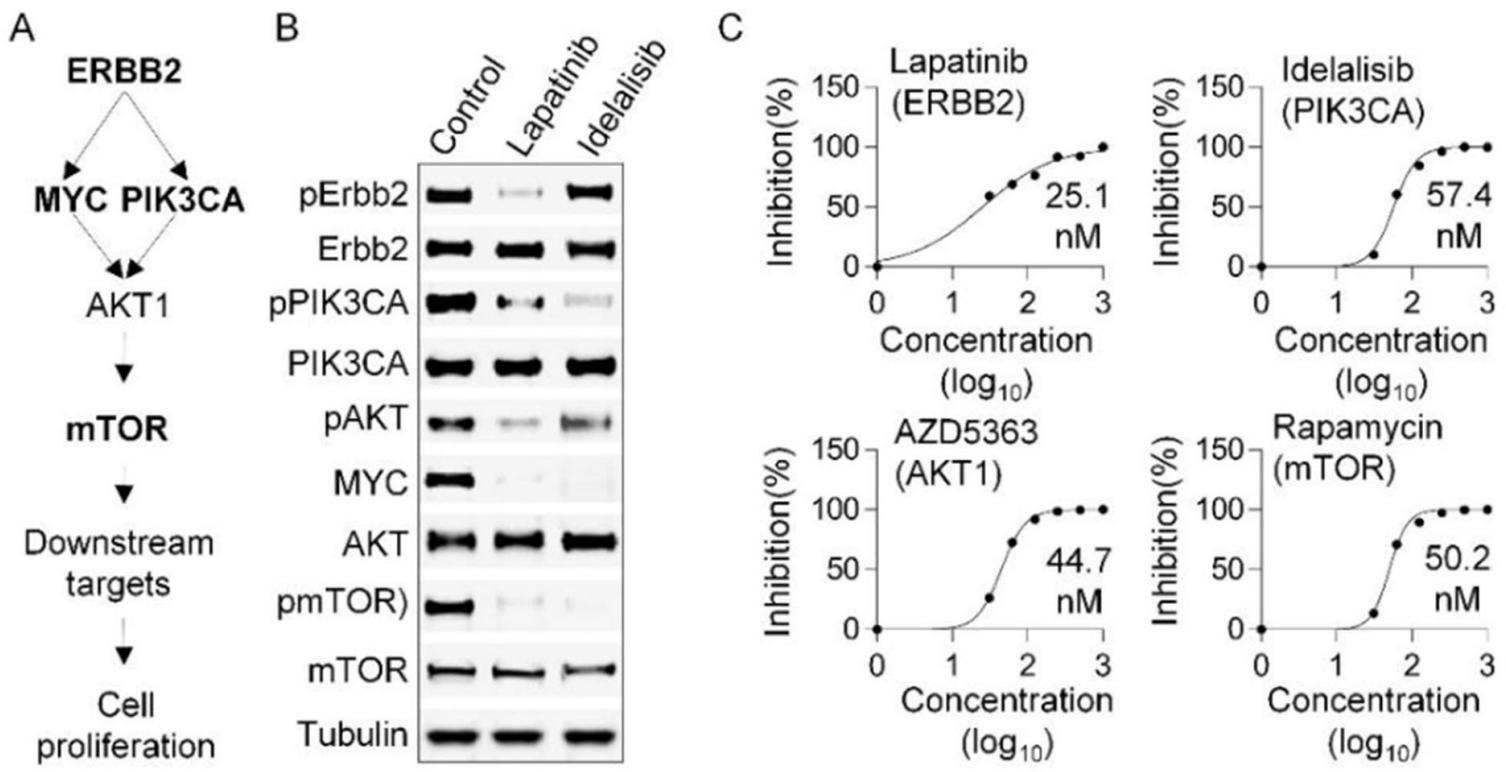

Figure 3. Disruption of ERBB2 and PI3K-AKT/mTOR signaling suppresses BBM cell survival. A: Schematic depicting the ERBB2/MYC/ AKT and PI3K-AKT/mTOR signaling pathways that affect BBM cell proliferation; B: cells were treated with ERBB2 (Lapatinib) and PI3K (Idelalisib) inhibitors at a final concentration of $100 \mathrm{nmol} / \mathrm{L}$ for $48 \mathrm{~h}$. Total protein lysates from were analyzed using antibodies specific to ERBB2, pERBB2, PIK3CA, pPIK3CA, AKT, pAKT, MYC, mTOR, and pmTOR. Tubulin was used as a loading control; C: BBM1 cells were treated with pharmaceutical inhibitors of ERBB2 (Lapatinib), PI3K (Idelalisib), AKT (AZD5363), and mTOR (Rapamycin) at final concentrations $0,31.2,62.5,125,250,500,1000 \mathrm{nmol} / \mathrm{L}$. Control cells were treated with DMSO only. The viability of the cells at $72 \mathrm{~h}$ post-treatment is shown. The $\mathrm{IC}_{50}$ values of the compounds are in the bottom right of each plot

10 days. We identified 35 compounds that showed robust toxicity towards both BBM1 and BBM2 cell lines, throughout the study period [Supplementary Figure 3].

Further screening was done to identify compounds with BBM cell-specific toxicity using both BBM1 and human reactive astrocytes cells. We identified 12 compounds that were at least two-fold more toxic towards BBM1 cells than toward astrocytes [Figure 4B and C]. Finally, we analyzed concentration-dependent toxicity and identified 6 compounds that showed linear concentration-dependent suppression of BBM1 cell viability. $\mathrm{IC}_{50}$ analysis revealed that Doxorubicin, a DNA-binding chemotherapeutic agent for multiple cancers, was the most toxic compound towards BBM1 cells. The SCR inhibitor $\left(\mathrm{AC}-93253 ; \mathrm{IC}_{50}=85 \mathrm{nmol} / \mathrm{L}\right)$ and GABA receptor agonist (Isoguvacine; $\mathrm{IC}_{50}=99.2 \mathrm{nmol} / \mathrm{L}$ ) showed greater toxicity than the Wnt agonist (CID11210285), sirtuin (SIRT) inhibitor (JDF00244), and leucine-rich repeat kinase-2 (LRRK2) inhibitor (GSK2578215A), which had $\mathrm{IC}_{50}$ values ranging from $183 \mathrm{nmol} / \mathrm{L}$ to $304 \mathrm{nmol} / \mathrm{L}$ [Figure $4 \mathrm{D}$ ]. Consistent with the drug screening data, our RNA-seq analysis indicated relatively higher expression of SRC in MT cells compared to nBrain and nBreast but not to PT [Supplementary Figure 4].

\section{Combinatorial inhibition of ERBB2 with an SRC or PIK3CA inhibitor or a GABA agonist induces robust apoptosis in BBM1 cells}

Bioinformatics analysis showed that SRC1 is an upstream regulator of ERBB2 and its targets, MYC and $\mathrm{PIK} 3 \mathrm{CA}$, and an activator of PI3K-AKT/mTOR signaling [Figure 5A], indicating that SCR1 potentially plays a critical role in BBM cell survival and proliferation. To confirm this function of SRC, we treated BBM1 cells with different inhibitors specific to SRC and its downstream targets for $48 \mathrm{~h}$. Apoptosis analysis showed that these inhibitors induced robust apoptosis in BBM1 cells [Figure 5B]. Further confirmation of apoptosis was obtained via Western blot analysis of procaspase3 and cleaved caspase3 proteins in the treated cells [Figure 5C].

Consistent with the RNA-seq data, our compound screening results indicated that SRC-mediated activation of the PIK3-AKT/mTOR pathway plays a critical role in BBM cell survival and proliferation. To confirm the 
A

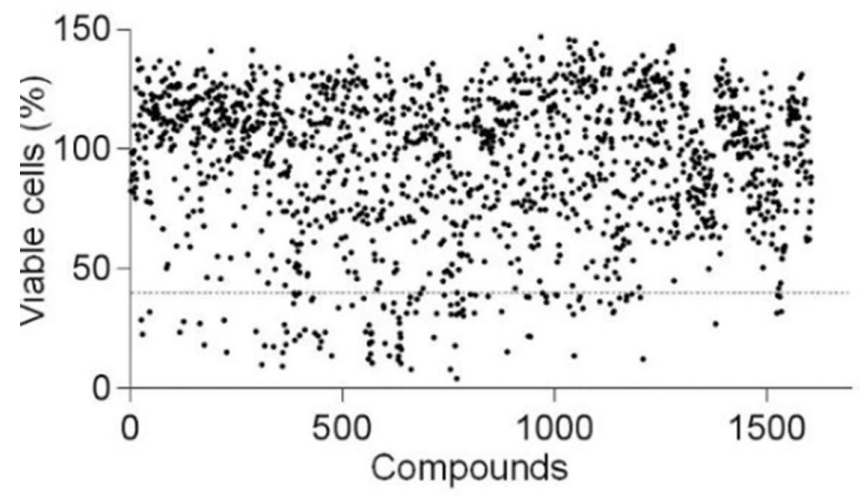

B

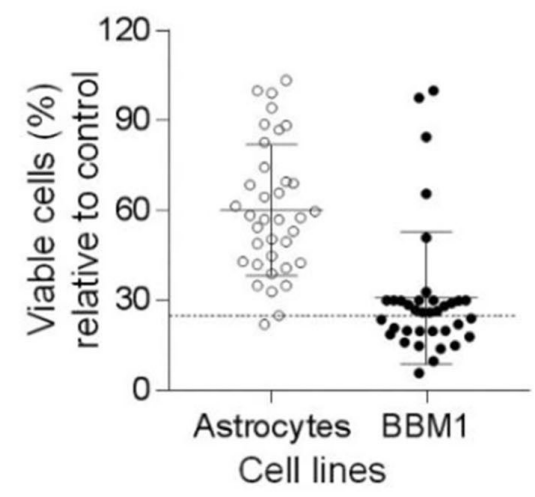

C

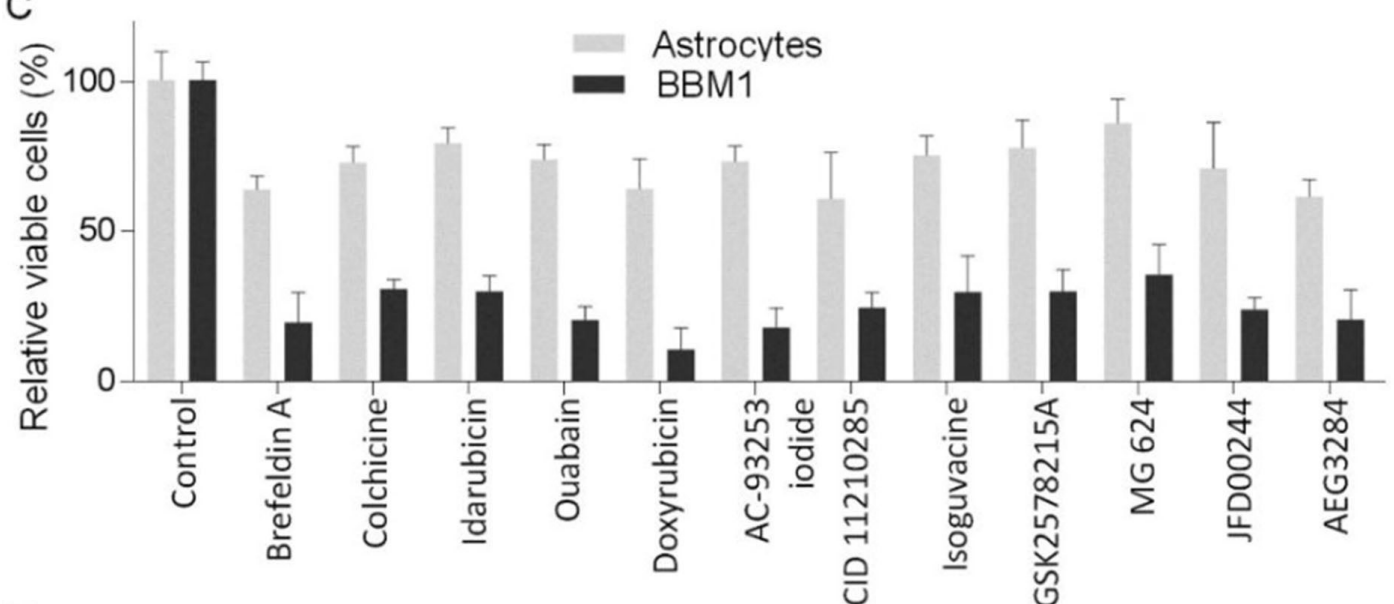

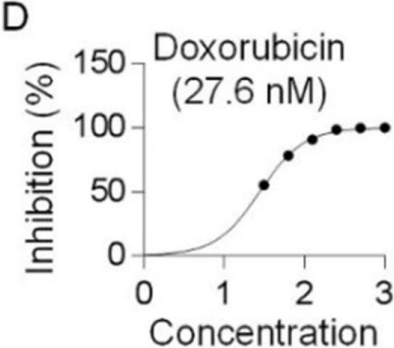

$\left(\log _{10}\right)$

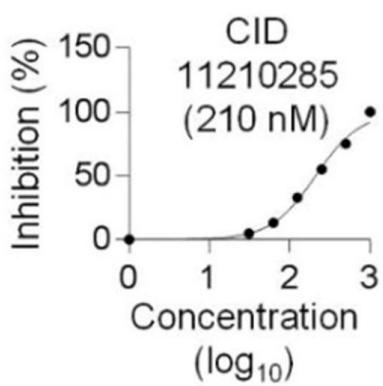

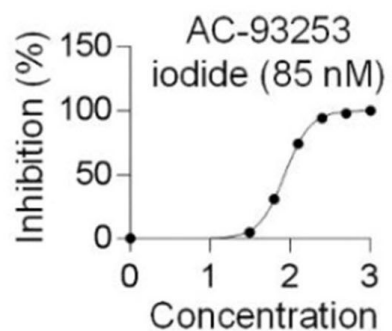

$\left(\log _{10}\right)$

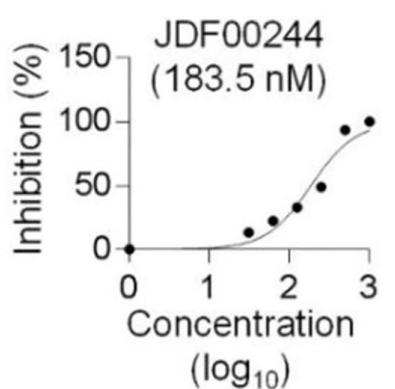

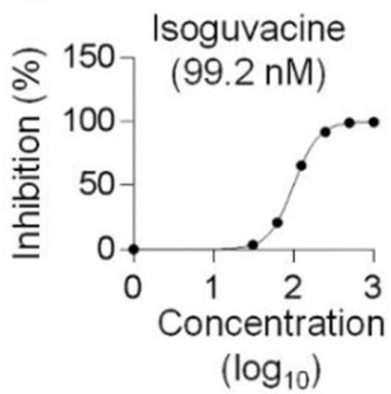

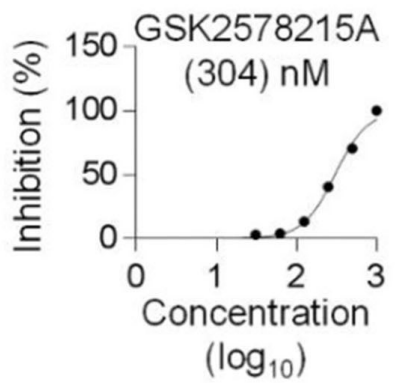

Figure 4. Screening of clinical and preclinical drugs to identify novel candidates targeting breast cancer brain metastases. A: Preliminary screening of 1,650 compounds for their efficacy against BBM1 cells. BBM1 cells were grown overnight prior to treatment with the compounds at a final concentration $1 \mu \mathrm{mol} / \mathrm{L}$ for 48 or $72 \mathrm{~h}(n=2)$. The percentages of viable cells in each treatment group relative to viable control cells treated with DMSO are shown for data collected after 72-h treatment. Compounds that suppressed viability below $70 \%$ compared to control (107 total, separated by a dashed line) were selected for secondary screening using both BBM1 and BBM2 cells lines; B, $\mathrm{C}$ : tertiary screening of the active compounds based on cell type-specific effects. Human astrocytes and BBM1 cells were grown overnight prior to treatment with the 35 active compounds identified in the secondary screening at a final concentration of $1 \mu \mathrm{mol} / \mathrm{L}$ for 48 or $72 \mathrm{~h}(n$ =6). The percentages of viable cells relative to viable control cells treated with DMSO are shown for data collected after 72 -h treatment; C: relative viability of BBM1 cells treated with compounds (12) that reduced BBM1 cell viability by at least two-fold compared to that of astrocytes at a concentration of $1 \mu \mathrm{mol} / \mathrm{L}$ for $72 \mathrm{~h}$; D: concentration-dependent effects of six potent active compounds. BBM1 cells were grown overnight prior to treatment with the compounds at final concentrations ranging from $0,31.2,62.5,125,250,500,1000 \mathrm{nmol} / \mathrm{L}(n=$ 8). The viability of the cells at $72 \mathrm{~h}$ post-treatment is shown. The IC 50 values of the compounds are shown in parenthesis 
SRC-mediated activation of PIK3/AKT/mTOR signaling, we treated BBM1 cells with $100 \mathrm{nmol} / \mathrm{L}$ of AC93253 for $48 \mathrm{~h}$, followed by Western blot analysis of the total protein extract. Our analysis showed that inhibition of SRC leads to inhibition of PIK3CA and mTOR phosphorylation [Figure 5D]. As our analysis indicated that SRC is an upstream regulator of ERBB2 and the PIK3-AKT/mTOR pathway in BBM1 cells and that inhibition of both SCR and ERBB2 induces BBM1 cell death, we analyzed the combined effect of SRC and ERBB2 inhibitors on BBM1 cell viability. We treat the cells with $50 \mathrm{nmol} / \mathrm{L}$ of AC93253 and $50 \mathrm{nmol} / \mathrm{L}$ of Lapatinib, separately and in combination, for $48 \mathrm{~h}$. Our analysis showed robust inhibition of BBM1 cells in the presence of either inhibitor alone, however, the effect was greatest in presence of both [Figure 5E]. Similar to combinatorial SRC/ERBB2 treatment, concurrent inhibition of ERBB2 and PIK3CA showed a significant additive inhibitory effect on BBM1 cell survival [Figure 5E].

We also evaluated the combinatorial treatment of ERBB2 and SRC inhibitors with a GABA agonist. BBM1 cells were treated with either $100 \mathrm{nmol} / \mathrm{L}$ of Isoguvacine alone or in combination with Lapatinib or AC93253 for $48 \mathrm{~h}$. Cell viability and apoptosis analyses showed that the combination of Isoguvacine with both Lapatinib and AC93253 induced higher inhibition of cell viability compared to independent treatments [Figure 6A and B]. Our analysis showed that the expression of GABA receptors and subunits was significantly higher in nBrain compared to PT, MT, and nBreast [Figure 6C, Supplementary Figure 5].

\section{DISCUSSION}

Brain metastases are the most common and complicated central nervous system disease in adults. The incidence of brain metastases is increasing due to both improved diagnosis and increased cancer patient survival through advanced systemic treatments. Outcomes of patients remain disappointing and treatment options are limited, usually involving multimodality approaches of radiation and palliative chemotherapy. Brain metastases represent an unmet clinical challenge in caring for solid tumor, especially in breast cancer, where the incidence of brain metastases are frequent and that result in impaired quality of life.

BBMs are common in patients with the HER2-positive and TNBC breast cancer subtypes, and the natural course of BBM is strongly influenced by the biology of the primary tumor subtype. Although the biology of BBM according to tumor subtypes is still poorly understood, recent breakthroughs have been achieved in the identification of specific mediators of BBM and in the development of preclinical models for therapeutic studies. However, the use of established cell lines and comparative analysis of unrelated tissue samples often identify factors that eventually fail to represent as a key regulator in preclinical and clinical stage. To overcome this issue we obtained both primary and metastasis tissue from same individual patients (PT1/ MT2 and PT2/MT2). Due to the inherent difficulty in the procurement of such tissue pairs we have used limited numbers of tissue samples. Our RNA-seq analysis revealed that ERBB2-mediated activation of PIK3CA and its downstream AKT/mTOR pathway plays a critical role in the survival and proliferation of breast to brain metastatic cells. Inhibition of ERBB2 or its downstream targets suppresses BBM cell viability to different degrees. The critical function of ERBB2 in HER2+ primary and metastatic breast cancer has been well established, and the ERBB2 inhibitor Lapatinib and trastuzumab have been used as chemotherapeutic agents targeting HER 2+ breast cancer ${ }^{[25-28]}$. In addition, our earlier studies revealed the contribution of neural factors, such as the astrocyte-secreted brain-derived neurotrophic factor, in the activation of HER2-TrkB signaling that leads to AKT1 activation and BBM1 cell proliferation ${ }^{[25]}$. Several studies have also reported mutations and/or copy number changes in PIK3CA in hormone receptor-positive breast cancers ${ }^{[29-31]}$. Indeed, targeting PIK3-AKT/mTOR signaling to inhibit breast cancer has been evaluated extensively, and there is phase I to III preclinical trial data demonstrating that inhibition of this pathway leads to regression of solid tumors and breast cancer ${ }^{[32-37]}$.

Recent gene expression analyses of BBM samples identifed cyclooxygenase (COX)-2, EGFR ligands, and a sialyltransferase, as mediators of cancer cell passage through the $\mathrm{BBB}^{[38]}$. In contrast to COX-2 and EGFR, 
A
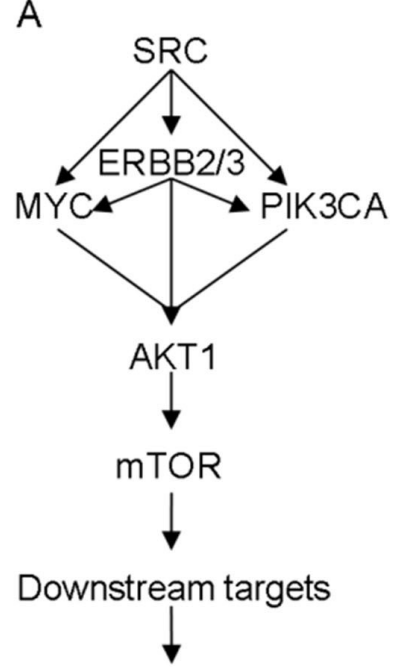

Cell proliferation
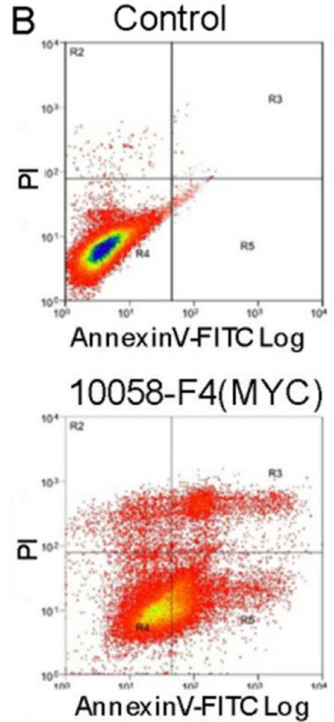
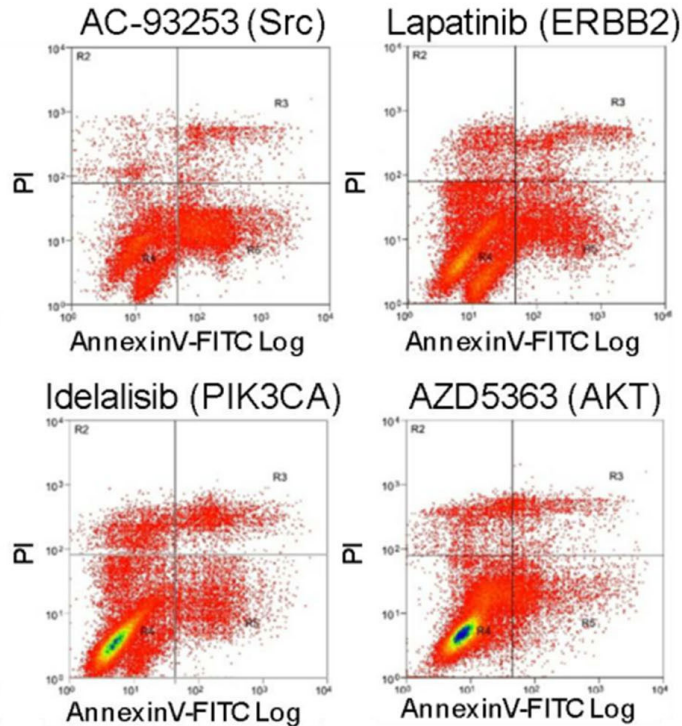

C
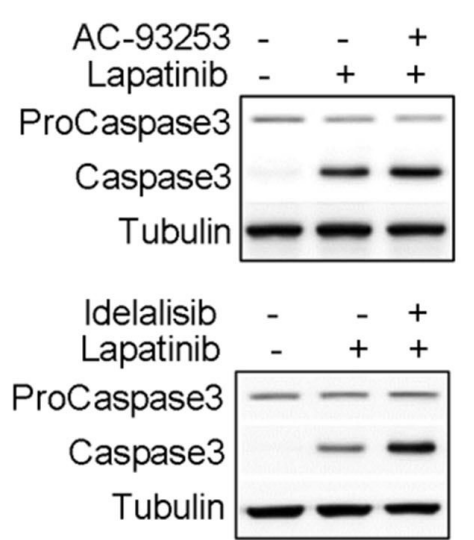
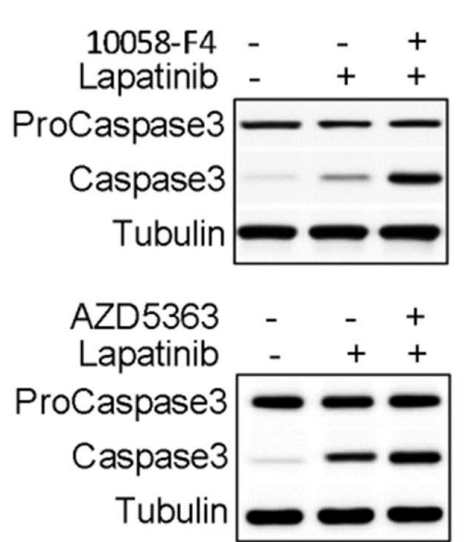

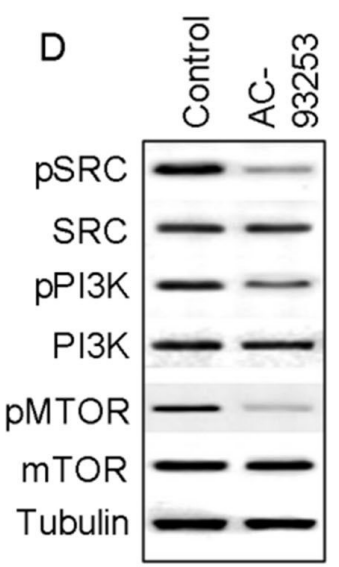

$\mathrm{E}$
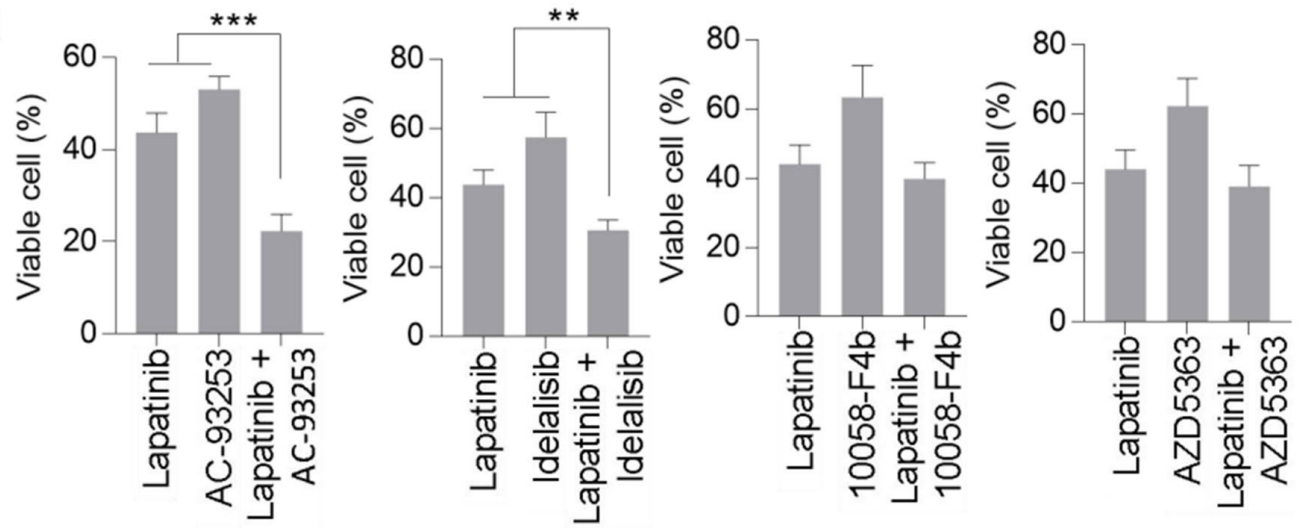

Figure 5. Inhibition of BBM1 cell proliferation by combinatorial treatment with the ERBB2 inhibitor Lapatinib and inhibitors of the PI3K-AKT/mTOR signaling pathway. A: Schematic depicting the functions of SRC, ERBB2, and PIK3CA in activating PIK3-AKT/mTOR signaling-mediated cell proliferation; B: effect of inhibition of SRC kinase, ERBB2, and PIK3-AKT/mTOR signaling on apoptosis induction in BBM1 cells. Cells were treated with inhibitors of SRC (AC-93253), ERBB2 (Lapatinib), MYC (10058-F4b), PIK3CA (Idelalisib), and AKT (AZD5363) at a final concentration of $100 \mathrm{nmol} / \mathrm{L}$ for $48 \mathrm{~h}$. Control cells were treated with DMSO alone. Apoptosis induction was measured using Annexin V-FITC staining followed by FACS analysis; C: cells were treated with inhibitors (100 nmol/L) for $48 \mathrm{~h}$, and total protein extracts were subjected to Western blot analysis using antibodies against ProCaspase3 (inactive) and cleaved Caspase3 (active). Tubulin was used as loading control; D: selective inhibition of the SRC kinase with AC-93253 disrupts PIK3-AKT/mTOR signaling. Cells were treated with AC-93253 (100 nmol/L) for $48 \mathrm{~h}$, and total protein lysates from the cells were analyzed using antibodies specific to SRC, pSRC, PI3K, pPI3K, mTOR, and pmTOR. Tubulin was used as loading control; E: effect of the ERBB2 inhibitor Lapatinib alone and in combination with SRC, PIK3CA, MYC, and AKT inhibitors on BBM1 cell viability. Cells were treated with $50 \mathrm{nmol} / \mathrm{L}$ Lapatinib alone or in combination with AC-93253, Idelalisib, 10058-F4b, or AZD5363 at a final concentration of $50 \mathrm{nmol} / \mathrm{L}$. The percentages of viable cells in each treatment group relative to viable control cells treated with DMSO are shown for data collected after $48 \mathrm{~h}$. Error bars indicate SEM ( $n$ $=3$, ${ }^{\star \star} P<0.05$; ${ }^{\star \star \star} P<0.01$ ) 
A

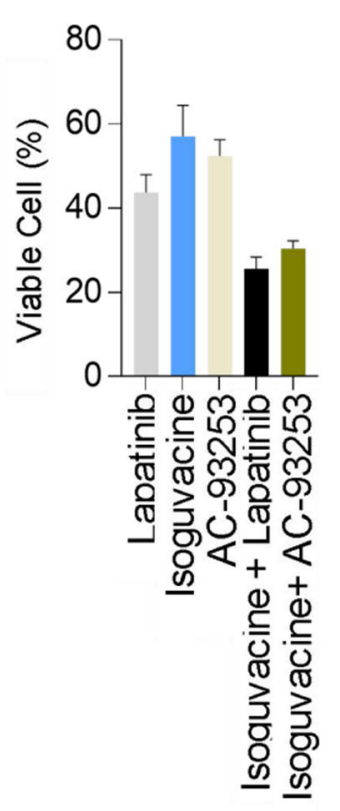

B
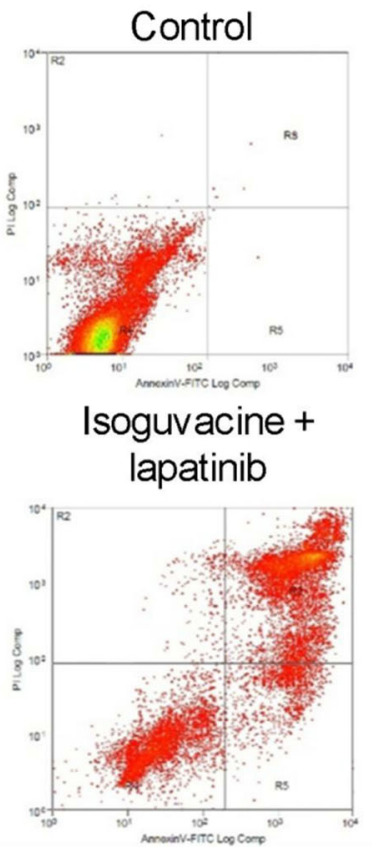

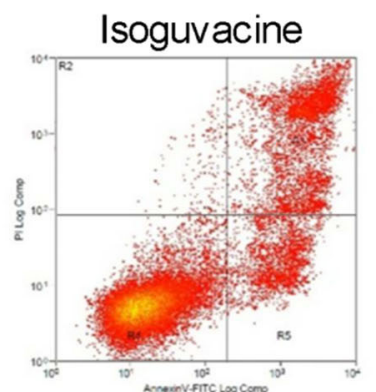

Isoguvacine

+ AC-93253

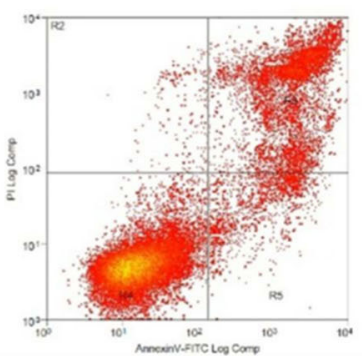

C

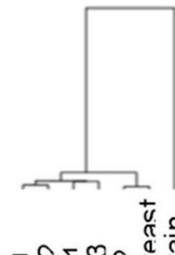

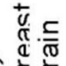

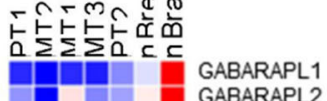

GABARAPL2

GABARAPL3

GABBR1

GABBR2

GABRA1

GABRA2

GABRA3

GABRA3

GABRA4

GABRA6

GABRB1

GABRB2

GABRB3

GABRD

GABRD

GABRG

GABRG2

GABRG3

Figure 6. Inhibition of BBM1 cell proliferation upon treatment with a GABA agonist alone and in combination with ERBB2 or SRC inhibitors. A: BBM1cells were treated with GABA agonist Isoguvacine, AC-93253, and/or Lapatinib at final concentrations of $100 \mathrm{nmol} / \mathrm{L}$. The percentages of viable cells in each treatment group relative to viable control cells treated with DMSO are shown for data collected after $48 \mathrm{~h}(n=3, P<0.05)$. Error bars indicate SEM; B: the induction of apoptosis was measured using Annexin V-FITC staining followed by FACS analysis. Control cells were treated with DMSO alone; C: hierarchical clustering based on the expression GABA receptors and subunits in primary breast cancer (PT1-2), breast to brain metastatic tumor tissue (MT1-3), normal breast tissue (nBreast), and normal brain tissue (nBrain). Low expression (blue), high expression (red)

which are also linked to other organ metastases, aberrant expression of ST6GALNAC5 specifically mediated BBM, potentially by enhancing adhesion circuating cells to the CNS endothelium. Similarly, using larger cohort of patient samples metastasis suppressor KISS1 a prognostic marker for increased risk of breast cancer progression was identified ${ }^{[39]}$. These concurrent genomic analysis indicates that an effective molecular target for complete remission of BBM is yet to be identified.

Supporting the RNA-seq data, our parallel screening of clinical and preclinical drug candidates identified ERBB2, PIK3CA, and their downstream targets as critical regulators of BBM cell proliferation. We identified SRC as an upstream regulator of ERBB2, PIK3CA, and MYC. Inhibition of each of SRC and ERBB2 alone or in combination with a GABA agonist-induced robust apoptosis in BBM1 cells.

The previous study also demonstrated that SRC is hyperactivated in brain-seeking breast cancer cells and that SRC activation promotes tumor cell extravasation into the brain parenchyma via permeabilization of the blood-brain barrier ${ }^{[21]}$. Indeed, the preclinical study showed that SRC and SRC family kinases mediate intracellular signaling pathways that control key biologic/oncogenic processes in glioblastoma ${ }^{[21]}$. In addition to neurotransmission and regulation of secretion, GABA through GABAA receptors negatively regulates proliferation of neural stem cells ${ }^{[23]}$. GABAergic signaling and its control over proliferation have also emerged as critical in brain tumors ${ }^{[40-42]}$.

Indeed, previous studies from our group showed that human breast cancer metastases to the brain display GABAergic properties in the neural niche and metabolize GABA as an energy source ${ }^{[40]}$. Consistent with previous findings on the inhibitory effects of GABA signaling on neural and embryonic stem cells ${ }^{[43,44]}$, our findings indicate that the attenuation of GABA signaling is potentially associated with the rapid proliferation of tumor cells in the brain. The activation of GABA signaling potentially reverses the availability of GABA as 
an energy source for GABAergic BBM cells, leading to suppression of viability and proliferation. Our results indicate that combinatorial treatment with a GABA agonist and SRC or ERBB2 inhibitors is a potentially effective therapeutic approach targeting BBM. Finally, consistent with the drug screening data, aberrant Wnt signaling is a hallmark of many cancers. Dysregulation of canonical and non-canonical Wnt signaling was reported in triple-negative breast cancer ${ }^{[45-47]}$. No previous studies have shown any relationship of SIRT and LRRK2 with HER2+ breast cancer brain metastasis. In conclusion, we have identified both molecular targets and active clinical/preclinical inhibitors to target breast cancer brain metastasis. In our future studies, we will evaluate the efficacy of these inhibitors in animal models in vivo.

\section{CONCLUSION}

The study reveals critical roles for SRC, ERBB2, PIK3CA, and GABA in the proliferation and survival of BBM cells and showed that SRC- and ERBB2-mediated activation of PIK3-AKT/mTOR signaling regulates BBM cell survival. Selective inhibition of these candidate genes alone or in combination induces robust apoptosis in BBM cells. In addition, the finding revealed that agonist-mediated activation of GABA signaling in combination with inhibition of SRC/ERBB2 signaling acts as an effective strategy to inhibit BBM cell proliferation. In future studies, we will analyze BBM cell-specific toxicity of the lead candidates alone or in combinations using larger numbers of BBM, primary breast cancer and glial cell lines. We will identify the candidates or combination with significantly higher BBM cell selective toxicity for preclinical evaluation using animal models. In conclusion, the findings of this study provide a rationale for further preclinical evaluation of SRC-targeting regimens in combination with ERBB2 inhibitors and/or GABA agonists to target breast cancer brain metastasis.

\section{DECLARATIONS}

\section{Acknowledgments}

We tender our heartfelt gratitude to Kerin Higa for critically evaluating and proofreading the manuscript. We acknowledge Integrative Genomics Core's sequencing service.

\section{Authors' contributions}

Made substantial contributions to conception and design of the study and performed data analysis and interpretation: Ansari SR, Jandial Z, Wu X, Liu X, Ansari KI

Performed data acquisition, as well as providing administrative, technical, and material support: Ansari SR, Jandial Z, Chen MY, Ansari KI

\section{Availability of data and materials}

Not applicable.

\section{Financial support and sponsorship}

This work was supported by Department of Defense Breast Cancer Research Program (BC142323); and the Margaret E. Early Medical Research Trust for experiment design, collection, analysis, and interpretation of data, and writing of the manuscript.

\section{Conflicts of interest}

All authors declared that there are no conflicts of interest.

\section{Ethical approval and consent to participate}

Not applicable.

\section{Consent for publication}

Not applicable. 


\section{Copyright}

(c) The Author(s) 2019.

\section{REFERENCES}

1. Swain SM, Baselga J, Miles D, Im YH, Quah C, et al. Incidence of central nervous system metastases in patients with HER2-positive metastatic breast cancer treated with pertuzumab, trastuzumab, and docetaxel: results from the randomized phase III study CLEOPATRA. Ann Oncol 2014;25:1116-21.

2. Brufsky AM, Mayer M, Rugo HS, Kaufman PA, Tan-Chiu E, et al. Central nervous system metastases in patients with HER2-positive metastatic breast cancer: incidence, treatment, and survival in patients from registHER. Clin Cancer Res 2011;17:4834-43.

3. Moliterni A, Mariani G, Stella GC, Mariani L, Bianchi GV, et al. Long-term results from INT-HER study: retrospective evaluation of adjuvant trastuzumab in unselected HER2-positive breast cancer patients-single institution experience. J Clin Oncol 2014;32.

4. Ow SGW, Yong YFL, Chieng WS, Phyu PS, Lee SC. Clinical outcome of HER2-positive breast cancer patients after failure on adjuvant trastuzumab: the potential of the time to relapse. Clin Oncol 2014;26:174-5.

5. Ramakrishna N, Temin S, Lin NU. Recommendations on disease management for patients with advanced human epidermal growth factor receptor 2-positive breast cancer and brain metastases: ASCO clinical practice guideline update summary. J Oncol Pract 2018;14:505-7.

6. Ramakrishna N, Temin S, Chandarlapaty S, Crews JR, Davidson NE, et al. Recommendations on disease management for patients with advanced human epidermal growth factor receptor 2-positive breast cancer and brain metastases: American Society of Clinical Oncology clinical practice guideline. J Clin Oncol 2014;32:2100-8.

7. Steeg PS, Camphausen KA, Smith QR. Brain metastases as preventive and therapeutic targets. Nat Rev Cancer 2011;11:352-63.

8. Stemmler HJ, Heinemann V. Central nervous system metastases in HER-2-overexpressing metastatic breast cancer: a treatment challenge. Oncologist 2008;13:739-50.

9. Lin NU, Carey LA, Liu MC, Younger J, Come SE, et al. Phase II trial of lapatinib for brain metastases in patients with human epidermal growth factor receptor 2-positive breast cancer. J Clin Oncol 2008;26:1993-9.

10. Lin NU, Dieras V, Paul D, Lossignol D, Christodoulou C, et al. Multicenter phase II study of lapatinib in patients with brain metastases from HER2-positive breast cancer. Clin Cancer Res 2009;15:1452-9.

11. Yap TA, Vidal L, Adam J, Stephens P, Spicer J, et al. Phase I trial of the irreversible EGFR and HER2 kinase inhibitor BIBW 2992 in patients with advanced solid tumors. J Clin Oncol 2010;28:3965-72.

12. Da Silva L, Simpson PT, Smart CE, Cocciardi S, Waddell N, et al. HER3 and downstream pathways are involved in colonization of brain metastases from breast cancer. Breast Cancer Res 2010;12:R46.

13. Kodack DP, Askoxylakis V, Ferraro GB, Fukumura D, Jain RK. Emerging strategies for treating brain metastases from breast cancer. Cancer Cell 2015;27:163-75.

14. Lin NU, Gelman RS, Younger WJ, Sohl J, Freedman RA, et al. Phase II trial of carboplatin (C) and bevacizumab (BEV) in patients (pts) with breast cancer brain metastases (BCBM). J Clin Oncol 2013;31.

15. Lu YS, Chen WW, Lin CH, Tseng LM, Yeh DC, et al. Bevacizumab, etoposide, and cisplatin (BEEP) in brain metastases of breast cancer progressing from radiotherapy: results of the first stage of a multicenter phase II study. J Clin Oncol 2012;30.

16. Bartsch R, Berghoff AS, Preusser M. Breast cancer brain metastases responding to primary systemic therapy with T-DM1. J Neurooncol 2014;116:205-6.

17. Krop IE, Kim SB, Gonzalez-Martin A, LoRusso PM, Ferrero JM, et al. Trastuzumab emtansine versus treatment of physician's choice for pretreated HER2-positive advanced breast cancer (TH3RESA): a randomised, open-label, phase 3 trial. Lancet Oncol 2014;15:689-99.

18. Verma S, Miles D, Gianni L, Krop IE, Welslau M, et al. Trastuzumab emtansine for HER2-positive advanced breast cancer. N Engl J Med 2012;367:1783-91.

19. Beadnell TC, Nassar KW, Rose MM, Clark EG, Danysh BP, et al. Src-mediated regulation of the PI3K pathway in advanced papillary and anaplastic thyroid cancer. Oncogenesis 2018;7:23.

20. Rexer BN, Ham AJL, Rinehart C, Hill S, Granja-Ingram ND, et al. Phosphoproteomic mass spectrometry profiling links Src family kinases to escape from HER2 tyrosine kinase inhibition. Oncogene 2011;30:4163-74.

21. Zhang SY, Huang WC, Zhang L, Zhang CY, Lowery FJ, et al. Src family kinases as novel therapeutic targets to treat breast cancer brain metastases. Cancer Res 2013;73:5764-74.

22. Du Y, Du Z, Zheng H, Wang D, Li S, et al. GABA exists as a negative regulator of cell proliferation in spermaogonial stem cells. Cell Mol Biol Lett 2013;18:149-62.

23. Young SZ, Bordey A. GABA's control of stem and cancer cell proliferation in adult neural and peripheral niches. Physiology (Bethesda) 2009;24:171-85.

24. Young SZ, Bordey A. GABA's control of stem and cancer cell proliferation in adult neural and peripheral niches. Physiology 2009;24:17185.

25. Choy C, Ansari KI, Neman J, Hsu S, Duenas MJ, et al. Cooperation of neurotrophin receptor TrkB and Her2 in breast cancer cells facilitates brain metastases. Breast Cancer Res 2017;19:51.

26. Opdam FL, Guchelaar HJ, Beijnen JH, Schellens JH. Lapatinib for advanced or metastatic breast cancer. Oncologist 2012;17:536-42.

27. Freedman RA, Hughes ME, Ottesen RA, Weeks JC, He Y, et al. Use of adjuvant trastuzumab in women with human epidermal growth factor receptor 2 (HER2)-positive breast cancer by race/ethnicity and education within the National Comprehensive Cancer Network. Cancer 2013;119:839-46.

28. Collins I, Francis P, Mileshkin L. Adjuvant trastuzumab in HER2-positive breast cancer. N Engl J Med 2012;366:664; author reply 664-6.

29. Chen L, Yang L, Yao L, Kuang XY, Zuo WJ, et al. Characterization of PIK3CA and PIK3R1 somatic mutations in Chinese breast cancer 
patients. Nat Commun 2018;9:1357.

30. Jensen JD, Knoop A, Laenkholm AV, Grauslund M, Jensen MB, et al. PIK3CA mutations, PTEN, and pHER2 expression and impact on outcome in HER2-positive early-stage breast cancer patients treated with adjuvant chemotherapy and trastuzumab. Ann Oncol 2012;23:2034-42.

31. Zardavas D, Te Marvelde L, Milne RL, Fumagalli D, Fountzilas G, et al. Tumor PIK3CA genotype and prognosis in early-stage breast cancer: a pooled analysis of individual patient data. J Clin Oncol 2018;36:981-90.

32. Paplomata E, O'Regan R. The PI3K/AKT/mTOR pathway in breast cancer: targets, trials and biomarkers. Ther Adv Med Oncol 2014;6:154-66.

33. Abraham J. PI3K/AKT/mTOR pathway inhibitors: the ideal combination partners for breast cancer therapies? Expert Rev Anticancer Ther 2015;15:51-68.

34. Bahrami A, Khazaei M, Shahidsales S, Hassanian SM, Hasanzadeh M, et al. The therapeutic potential of PI3K/Akt/mTOR inhibitors in breast cancer: rational and progress. J Cell Biochem 2018;119:213-22.

35. Chia S, Gandhi S, Joy AA, Edwards S, Gorr M, et al. Novel agents and associated toxicities of inhibitors of the pi3k/Akt/mtor pathway for the treatment of breast cancer. Curr Oncol 2015;22:33-48.

36. Ghayad SE, Cohen PA. Inhibitors of the PI3K/Akt/mTOR pathway: new hope for breast cancer patients. Recent Pat Anticancer Drug Discov 2010;5:29-57.

37. Lee JJ, Loh K, Yap YS. PI3K/Akt/mTOR inhibitors in breast cancer. Cancer Biol Med 2015;12:342-54.

38. Bos PD, Zhang XH, Nadal C, Shu W, Gomis RR, et al. Genes that mediate breast cancer metastasis to the brain. Nature 2009;459:1005-9.

39. Ulasov IV, Kaverina NV, Pytel P, Thaci B, Liu F, et al. Clinical significance of KISS1 protein expression for brain invasion and metastasis. Cancer 2012;118:2096-105.

40. Neman J, Termini J, Wilczynski S, Vaidehi N, Choy C, et al. Human breast cancer metastases to the brain display GABAergic properties in the neural niche. Proc Natl Acad Sci U S A 2014;111:984-9.

41. Smits A, Jin Z, Elsir T, Pedder H, Nister M, et al. GABA-A channel subunit expression in human glioma correlates with tumor histology and clinical outcome. PLoS One 2012;7:e37041.

42. Quail DF, Joyce JA. The microenvironmental landscape of brain tumors. Cancer Cell 2017;31:326-41.

43. Pontes A, Zhang Y, Hu W. Novel functions of GABA signaling in adult neurogenesis. Front Biol (Beijing) 2013;8.

44. Berg DA, Belnoue L, Song H, Simon A. Neurotransmitter-mediated control of neurogenesis in the adult vertebrate brain. Development 2013;140:2548-61.

45. Pohl SG, Brook N, Agostino M, Arfuso F, Kumar AP, et al. Wnt signaling in triple-negative breast cancer. Oncogenesis 2017;6:e310.

46. Bilir B, Kucuk O, Moreno CS. Wnt signaling blockage inhibits cell proliferation and migration, and induces apoptosis in triple-negative breast cancer cells. J Transl Med 2013;11:280.

47. King TD, Suto MJ, Li YH. The wnt/beta-catenin signaling pathway: a potential therapeutic target in the treatment of triple negative breast cancer. J Cell Biochem 2012;113:13-8. 